Kristina Schee, ${ }^{*}$ Øystein Fodstad, ${ }^{* \dagger}$ and Kjersti Flatmark ${ }^{\star \neq}$

From the Department of Tumor Biology, Institute for Cancer Research," the Medical Faculty, Faculty Division, ${ }^{\dagger}$ and the Department of Surgical Oncology, The Norwegian Radium Hospital, Oslo University Hospital, Oslo, Norway

Colorectal cancer is a leading cause of cancer-related morbidity and mortality in the Western world. While improved diagnostic surveillance and treatment strategies involving surgery, chemo-, and radiotherapy have all contributed to earlier detection and improved survival, treatment decisions are still made almost exclusively based on the cancer's clinicopathological stage at diagnosis. Therefore, the search for new biomarkers to facilitate early diagnosis and individualized treatment is particularly warranted. MicroRNAs (miRNAs) are short, noncoding RNAs that regulate gene expression through posttranscriptional interactions with mRNA, thereby potentially leading to a vast range of downstream effects that depend on the target proteins affected. The discovery that miRNAs may act as either oncogenes or tumor suppressors has initiated extensive research in the cancer field, leading to the identification of numerous miRNAs implicated in carcinogenesis and tumor progression. MiRNAs are chemically stable and can thus be detected in a broad range of clinical samples, making these molecules particularly attractive as potential biomarkers in cancer. While the knowledge of miRNA involvement in colorectal cancer biology is less extensive than for other cancer types and several targets with potential biological and clinical relevance have been identified, a significant amount of research is still needed. In this review, we explore the literature regarding the relevance of miRNAs in colorectal cancer, focusing in particular on miRNAs as potential diagnostic, prognostic, and predictive biomarkers. ( $\mathrm{Am} \mathrm{J}$ Pathol 2010, 177:1592-1599; DOI: 10.2353/ajpath.2010.100024)

Colorectal cancer (CRC) is a leading cause of cancerrelated morbidity and mortality in the Western world, occurring almost equally in men and women. Intensified diagnostic surveillance along with improved treatment strategies involving surgery, chemo-, and radiotherapy have contributed to earlier detection and improved survival from CRC. However, almost $50 \%$ of patients diagnosed with CRC will die of the disease, mainly because of metastasis development, most commonly in the liver and lungs. Although extensive research has attempted to identify useful prognostic and predictive tools in CRC, treatment decisions are still almost exclusively based on tumor stage as determined by radiological and/or pathological evaluation. This shortcoming results in failure to identify high- and low-risk patients, and patients may receive either insufficient or unnecessary treatment, respectively. Thus, with the aim of achieving earlier detection and better tailoring of treatment in CRC outcome, the search for new biomarkers is highly warranted.

MicroRNAs (miRNA) are short (20-22nt) noncoding RNAs which regulate gene expression posttranscriptionally. The first miRNA was discovered in 1993 in the nematode Caenorhabditis elegans, ${ }^{1}$ where it was found to regulate postembryonic development. After their discovery miRNAs have been identified in plants, viruses, animals, and humans, and many have been evolutionary conserved between species, underscoring their pivotal biological role. More than 700 human miRNAs have been discovered to date, and the number is increasing rapidly (http://microrna.sanger.ac.uk/sequences/index.shtml, last accessed January 15,2010$).{ }^{2}$ Studies have shown that miRNA expression levels differ between normal and tumor tissues and vary among tumor types. ${ }^{3}$ The implication that they play an important role in oncogenesis has led to the notion of miRNA as potential biomarkers in early diagnosis of cancer, predicting prognosis or treatment response or even as targets in cancer treatment strategies. ${ }^{4}$ This review will briefly introduce miRNA biogenesis and function, suggested importance in cancer, and further explore the potential utility of miRNAs as biomarkers and therapeutic tools in CRC.

Supported by grants from South-Eastern Norway Regional Health Authority and from the Norwegian Foundation for Health and Rehabilitation.

Accepted for publication May 28, 2010.

CME Disclosure: None of the authors declared any relevant financial relationships.

Address reprint requests to Kjersti Flatmark, M.D., Ph.D., Department of Tumor Biology, Institute for Cancer Research, The Norwegian Radium Hospital, Oslo University Hospital, N-0310 Oslo, Norway. E-mail: kjersti. flatmark@rr-research.no. 


\section{MiRNA Biogenesis and Function}

MiRNAs are transcribed by polymerase II and then cleaved by the RNaselll enzyme Drosha into precursor miRNA (premiRNA) which are 60-70 nucleotide stem-loop structures. ${ }^{5}$ Pre-miRNAs are transported out of the nucleus and further processed by another RNaselll enzyme, Dicer, to generate the mature double-stranded product, from which one strand is incorporated into the RNA-induced silencing complex (RISC) to form miRISC. Negative regulation by miRNA can either lead to translational inhibition or transcript degradation depending on the complementarities between the miRNA and the $3^{\prime}$-untranslated region of the target mRNA. ${ }^{6}$ Imperfect pairing results in weak binding between miRNA and mRNA, followed by translation inhibition, while high degree of complementarity results in strong binding, giving the miRISC access to mRNA for degradation by proteolytic cleavage. Interestingly, although translation inhibition is the best described outcome of miRNA activity, opposite effects have been shown. Thus it was demonstrated that miRNAs could activate translation in response to experimentally induced quiescence via miRNA target sites in AU-rich elements in the 3'untranslated region of the tumor necrosis factor $\alpha$ mRNA, ${ }^{7}$ further illustrating the biological diversity of miRNAs.

Because miRNAs can bind with different degrees of complementarity, these molecules can recognize and bind a variety of mRNAs to potentially regulate translation, and ultimately the expression of corresponding proteins. This again implies that changes in the expression level of a specific miRNA could in principle influence several biological pathways, either positively or negatively, depending on the activity of the proteins affected. Also, as imperfect strand pairing may inhibit translation without affecting mRNA integrity, miRNA action may explain observed discrepancies between mRNA and protein expression levels, and knowledge of miRNA expression and function may increase the understanding of regulation of protein expression. Notably, the small size and stem-loop structure of miRNA render these molecules less prone to degradation by RNAses than mRNAs, and are thus likely to be conserved and amenable for detection in body fluids such as blood, pleural and peritoneal effusions, and urine. ${ }^{8}$ Because the number of identified miRNAs is relatively low ( 700) compared to the several thousand known mRNAs, the task of gaining an overview of miRNA expression is less complicated, while downstream regulatory action is potentially highly complex. By identifying conserved complementarity of mRNA with that of miRNA, it has been suggested that up to $30 \%$ of the human genome may be regulated by miRNAs, ${ }^{9}$ indicating that miRNAs are indeed potentially important regulators of biological processes and clarification of their role in various diseases such as cancer is warranted.

\section{MiRNA and Colorectal Cancer}

MiRNAs are involved in multiple biological pathways that can influence tumor formation and progression ${ }^{10-13}$ and can act either as oncogenes or tumor suppressors, de- pending on the downstream effects elicited by affected mRNA. Even if the complexity of miRNA function is still incompletely understood, miRNAs have been associated with several important molecular players and pathways relevant in carcinogenesis and tumor progression through work involving experimental models and clinical studies in different cancer types, including CRC. Results from expression analyses indicate that specific miRNAs are associated with disease stage and survival in several tumor types, such as chronic lymphocytic leukemia, prostate cancer, breast cancer, nonsmall cell lung cancer, and CRC. ${ }^{14-17}$ Although research into the relevance of miRNA expression in CRC has been less extensive than in other cancer types, several miRNAs have been identified with potential biological and clinical relevance in CRC (Table 1). The main points of interest have been divided between studying miRNA expression levels, exploring functions of differentially expressed targets and determining how this information can be used for diagnostic purposes, and for predicting prognosis and treatment response. In the following, we attempt to give an overview of current knowledge regarding the significance of miRNAs in CRC with particular attention to the potential utility of miRNA as biomarkers exemplified in Figure 1.

\section{Differential Expression of miRNAs in CRC}

Differential expression of a molecule in tumor and normal tissues often represents an important basis for cancer biomarker exploration and development. For diagnostic biomarkers, one would commonly focus on overexpressed targets, while for prognostic and predictive biomarkers, as well as for defining potential therapeutic targets, both over- and underexpression could be biologically interesting. In general, miRNA expression levels have been shown to be decreased in cancerous compared to corresponding normal tissue. ${ }^{3}$ Moreover experimental global repression of miRNA biogenesis in cancer cell lines promoted proliferation and invasion in vitro and increased tumor growth and metastasis development in animal models. ${ }^{26}$ However, contrasting these findings are numerous studies on clinical samples showing that specific miRNAs can be differentially up- and down-regulated in different cancer types. ${ }^{4,27-29}$

Among the first miRNAs to be studied in CRC were miR-143 and miR-145, which were both reported to be down-regulated in cancers compared to corresponding normal tissue. ${ }^{23,30}$ One of the suggested targets of miR143 is the MAP kinase ERK5, which is involved in cancer relevant processes such as proliferation and differentiation. ${ }^{27,31,32}$ When CRC cell lines (DLD-1 and SW480) were transfected with pre-miR-143, ERK5 was down-regulated and cell growth was significantly inhibited in a dose-dependent manner. ${ }^{31}$ Thus, reduced expression of miR-143 could be associated with tumorigenesis through elevated levels of ERK5. MiR-145 has been shown to target insulin receptor substrate 1 (IRS-1) and type I insulin-like growth factor receptor (IGF-IR), which sends antiapoptotic signals and promotes cell growth, and its low expression in CRC could be hypothesized to promote 
Table 1. MiRNAs That Are Differentially Expressed in Colorectal Cancer (CRC) Samples Compared to Normal Tissues and Suggested Clinical Relevance

\begin{tabular}{|c|c|c|c|c|c|c|}
\hline miRNA & $\begin{array}{c}\text { Expression } \\
\text { in CRC } \\
\text { versus } \\
\text { normal }\end{array}$ & $\begin{array}{l}\text { Patients } \\
\quad(n)\end{array}$ & $\begin{array}{l}\text { miRNA detection } \\
\text { method }\end{array}$ & $\begin{array}{l}\text { Clinical } \\
\text { relevance }\end{array}$ & Comment & Reference \\
\hline Let-7 & Up & 46 & RT-PCR & CT response & $\begin{array}{l}\text { Low expression associated with } \\
\text { improved response to folate- } \\
\text { based CT }\end{array}$ & 18 \\
\hline$m i R-17-5 p$ & Up & 110 & RT-PCR & DFS & $\begin{array}{l}\text { Low expression associated with } \\
\text { increased DFS in low-stage } \\
\text { disease (TNM } 1 \text { and 2) }\end{array}$ & 19 \\
\hline miR-20a & Up & 197 & $\mu \mathrm{A}$ and RT-PCR & $\mathrm{No}^{*}$ & $\begin{array}{l}\text { High expression associated with } \\
\text { poor OS in test cohort }\end{array}$ & 17 \\
\hline miR-29a & Up & 157 & RT-PCR & Plasma marker & $\begin{array}{l}\text { Upregulation as a diagnostic } \\
\text { marker }\end{array}$ & 20 \\
\hline \multirow[t]{3}{*}{ miR-21 } & Up & 22 & RT-PCR & NA & & 21 \\
\hline & & 197 & $\mu \mathrm{A}$ and RT-PCR & OS & $\begin{array}{l}\text { High expression associated with } \\
\text { poor OS }\end{array}$ & 17 \\
\hline & & 29 & RT-PCR & Tumor stage & $\begin{array}{l}\text { High expression associated with } \\
\text { advanced tumor stage }\end{array}$ & 22 \\
\hline \multirow[t]{3}{*}{ miR-31 } & Up & 98 & RT-PCR & Tumor stage & $\begin{array}{l}\text { High expression associated with } \\
\text { advanced tumor stage }\end{array}$ & 23 \\
\hline & & 12 & RT-PCR & Tumor stage & $\begin{array}{l}\text { High expression associated with } \\
\text { advanced tumor stage }\end{array}$ & 24 \\
\hline & & 29 & RT-PCR & $\begin{array}{l}\text { Tumor } \\
\text { differentiation }\end{array}$ & $\begin{array}{l}\text { Low expression associated with } \\
\text { poorly differentiated tumors }\end{array}$ & 22 \\
\hline \multirow[t]{2}{*}{ miR-92a } & Up & 90 & RT-PCR & Plasma marker & $\begin{array}{l}\text { Upregulation as a diagnostic } \\
\text { marker }\end{array}$ & 25 \\
\hline & & 157 & RT-PCR & Plasma marker & $\begin{array}{l}\text { Upregulation as a diagnostic } \\
\text { marker }\end{array}$ & 20 \\
\hline \multirow[t]{2}{*}{ miR-106a } & Down & 110 & RT-PCR & DFS and OS & $\begin{array}{l}\text { Downregulation associated with } \\
\text { shorter DFS }\end{array}$ & 19 \\
\hline & Up & 197 & $\mu \mathrm{A}$ and RT-PCR & $\mathrm{No}^{*}$ & $\begin{array}{l}\text { High expression associated with } \\
\text { poor OS in test cohort }\end{array}$ & 17 \\
\hline miR-126 & Down & 110 & RT-PCR & No & & 19 \\
\hline \multirow[t]{2}{*}{ miR-143 } & Down & 98 & RT-PCR & NA & & 23 \\
\hline & & 29 & RT-PCR & Tumor size & $\begin{array}{l}\text { Low expression associated with } \\
\text { large tumor size }\end{array}$ & 22 \\
\hline \multirow[t]{2}{*}{ miR-145 } & Down & 98 & RT-PCR & NA & & 23 \\
\hline & & 29 & RT-PCR & Tumor size & $\begin{array}{l}\text { Low expression associated with } \\
\text { large tumor size }\end{array}$ & 22 \\
\hline \multirow[t]{2}{*}{$\operatorname{miR}-181 b$} & Up & 197 & $\mu \mathrm{A}$ and RT-PCR & $\mathrm{No}^{*}$ & $\begin{array}{l}\text { High expression associated with } \\
\text { poor OS in test cohort }\end{array}$ & 17 \\
\hline & & 46 & RT-PCR & CT response & $\begin{array}{l}\text { Low expression associated with } \\
\text { improved response to folate- } \\
\text { based CT }\end{array}$ & 18 \\
\hline miR-203 & Up & 197 & $\mu \mathrm{A}$ and RT-PCR & $\mathrm{No}^{*}$ & $\begin{array}{l}\text { High expression associated with } \\
\text { poor OS in test cohort }\end{array}$ & 17 \\
\hline
\end{tabular}

CT indicates chemotherapy; DFS, disease-free survival; $\mu \mathrm{A}$, microarray analysis; OS, overall survival; NA, not assessed.

*These miRNAs were selected for association with OS in the test set, but the correlation was not confirmed in the validation set.

proliferation through this mechanism. ${ }^{33}$ In a study of 29 primary CRC samples, low expression of miR-143 and miR-145 was associated with large primary tumor size, supporting the suggested role of these molecules in CRC biology. ${ }^{22}$ MiR-126 was shown to be down-regulated in CRC compared to normal tissue through unknown mechanisms. ${ }^{19}$ In vitro studies have suggested that one target for miR-126 may be the $\mathrm{p} 85 \beta$ subunit, a component in the phosphatidylinositol 3-kinase signaling network, and loss of negative regulation by miR-126 could to lead to a selective growth advantage during colon carcinogenesis. ${ }^{34}$

One explanation offered to explain reduced miRNA expression levels in human cancer is that many miRNA encoding genes are located in clusters at fragile sites in the genome, which are commonly methylated or deleted in cancer. ${ }^{35}$ In CRC, p53 targets miR-34b and miR-34c were shown to be epigenetically silenced through methylation of neighboring $\mathrm{CpG}$ islands. ${ }^{36}$ This particular methylation pattern was present in $90 \%$ of examined CRC specimens (101 of 111), but not in corresponding normal tissue, and $\mathrm{miR}-34 \mathrm{~b} / \mathrm{c}$ were shown to be down-regulated in $\mathrm{CRC}$ cell lines and tumors. This suggests that miR34b/c could be important mediators of p53-dependent tumor suppression in colorectal epithelium, and that their epigenetic silencing may be a potential mechanism in CRC carcinogenesis.

Three independent groups have reported up-regulation of miR-31 in CRC, but the clinical significance is unclear, as are the biological functions of this molecule, because no mRNA targets have so far been verified for miR-31. Over-expression was associated with advanced tumor stage in two of the reports, ${ }^{23,24}$ while in the third 

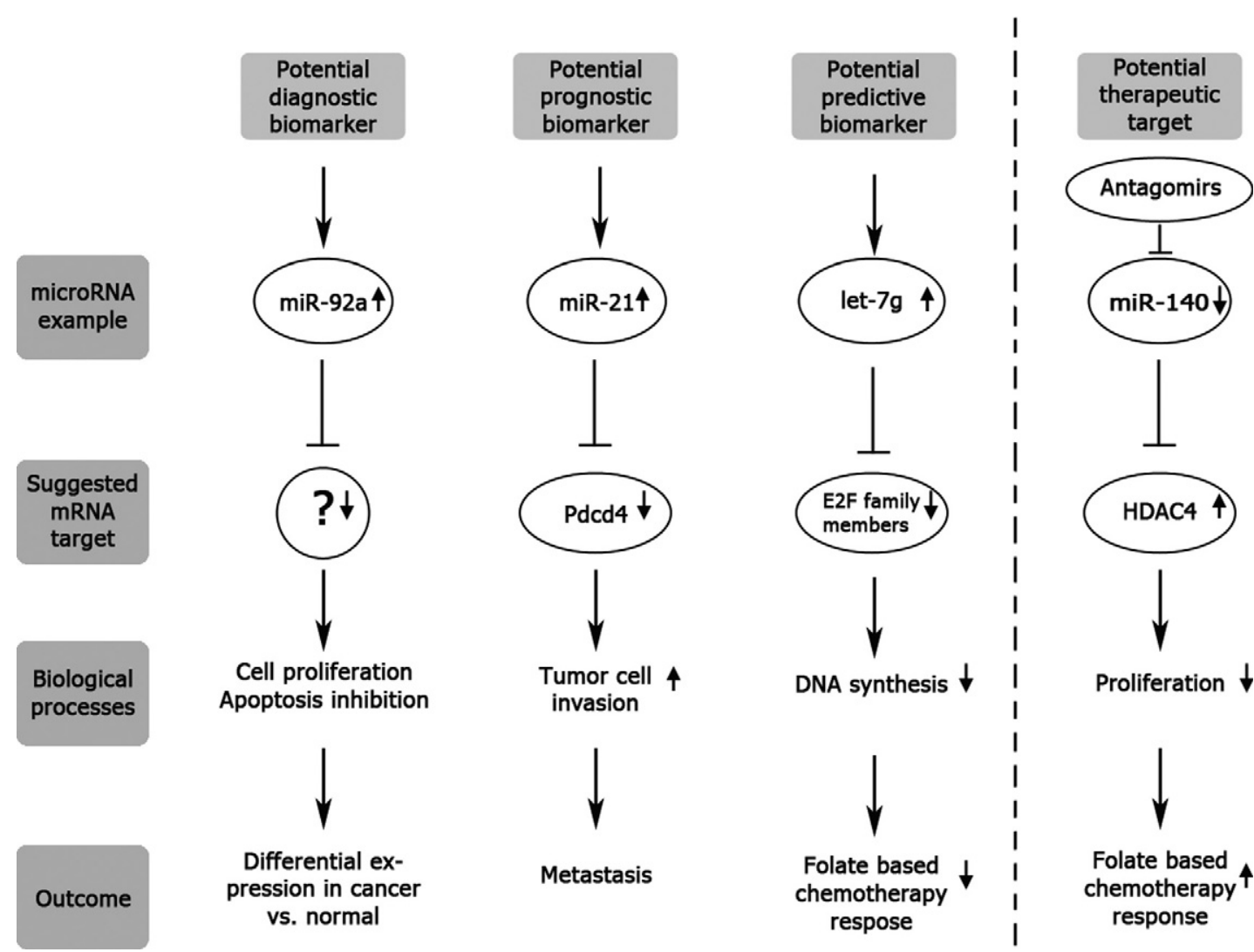

Figure 1. Potential uses of miRNAs as biomarkers of diagnosis, prognosis, and therapy response and as possible therapeutic target.

study, no correlation was observed between miR-31 expression and tumor stage. ${ }^{22}$ The discrepancy could be explained by the low number of cases included in two of the three studies ( $n=29$ and $n=12$ ), underscoring the importance of study design when aiming to determine the clinical relevance of molecular targets, particularly with regard to sample size.

The most comprehensive analysis of miRNA expression in CRC performed to date used microarrays containing 389 miRNA probes, and 37 miRNAs exhibited differential expression in the training set of 84 colon cancer samples. ${ }^{17}$ In particular, miR-20a, miR-21, miR-106a, miR-181b, and miR-203 were found to be overexpressed in tumor tissues with high tumor to normal ratios, as well as being associated with poor overall survival in the testing set. Prognostic relevance could be confirmed in the validation set for only one of the candidate miRNA (miR-21, see discussion below), and the clinical and biological implications of differential expression of the remaining miRNAs are unclear.

Although clinical relevance has not been verified for the differentially expressed miRNAs discussed in this section, the targets of many of these molecules are associated with pathways and processes relevant for CRC carcinogenesis and progression. Several of the mentioned studies were hampered by suboptimal design, and lack of significant correlations should not discourage inclusion of some of these candidate molecules in future studies in the search for potential biomarkers in CRC.

\section{MiRNA as Diagnostic Biomarkers in CRC}

The only current CRC biomarker in serum and plasma is carcinoembryonal antigen, but low specificity and sensitivity limits its clinical use, particularly for early detection of CRC. MiRNAs have been shown to be stably and differentially present in serum and plasma of cancer patients, and additionally, studies are ongoing to clarify the potential use as biomarkers in extracellular biological materials such as stool and urine..$^{8,37-39}$

Based on high expression levels in tumors and plasma from CRC patients and after a selection process starting with 95 miRNAs, miR-17-3p and miR-92a were chosen for further study in plasma from CRC patients $(n=90)$, healthy donors $(n=50)$, and patients with inflammatory bowel disease $(n=20)$ and gastric cancer $(n=20){ }^{25}$ High expression of both miRNAs was associated with the presence of CRC, but miR-92a was by far the best performer in statistical analyses. MiR-92a expression levels discriminated CRC patients from healthy controls with a quite promising sensitivity of $89 \%$ and specificity of $70 \%$. However no correlation was observed with tumor stage in the CRC patients. Interestingly, miR-92a expression was lower in inflammatory bowel disease than in controls, and levels in gastric cancer patients were equal to controls. The conclusions from this report, suggesting miR-92a as a possible biomarker for early detection of CRC were corroborated by a recent study of plasma samples from 100 CRC patients in which miR-92a was also found to be 
elevated relative to controls along with a second candidate miRNA, miR-29a. ${ }^{20}$ MiR-92a has been shown to be overexpressed in many solid tumors, and as part of the mir-17-92 gene cluster, which is a known oncomir, it may contribute to promote cell proliferation, inhibit apoptosis, and induce tumor angiogenesis. The biological explanation for the presence of miRNA in serum and plasma is incompletely understood, but recent work suggests that miRNA is secreted from cells and transported in the blood in exosomes, and may affect the recipient cells by inhibiting mRNA translation. ${ }^{39,41}$ A stage independent, sensitive, and specific marker for CRC in plasma would be clinically important, and clearly these promising results support further assessment of miRNAs as potential biomarkers in extracellular fluids.

The most widely applied screening method for CRC is the fecal occult blood test, but interpretation of results is hampered by low test specificity. However, the principle of detecting products shed from a tumor located in the colorectum into the stool offers the possibility of increased diagnostic sensitivity and specificity compared to blood tests, and attempts have been made to identify targets for such purposes. Among candidate molecules are miRNA because of their unique stability, and in a recent study, the levels of 15 miRNAs were measured in stool and colorectal tissue samples from 15 patients with $\mathrm{CRC}$ and 5 healthy individuals. ${ }^{42}$ Although the variability was more pronounced among the stool samples than the tissue samples, the authors concluded that specific miRNA expression profiles could be defined, suggesting that stool is yet another biological material in which miRNAs are preserved and amenable for detection.

\section{MiRNA as Prognostic Biomarkers in CRC}

The search for prognostic biomarkers in CRC has in recent years been extended to study the potential of analyzing expression of single or multiple miRNAs in tumor tissue, and in the following individual miRNAs which have been shown to have prognostic relevance in CRC will be discussed.

From the 37 miRNAs identified as differentially expressed in the previously mentioned microarray profiling study, overexpression of miR-21 was identified as an independent predictor of overall survival (OS) in the validation set containing tumor samples from 113 colon cancer patients. ${ }^{17}$ Similar conclusions were drawn from a study of 29 tumor samples, in which miR-21 expression was associated with poor survival and therapeutic outcome in stage II and III CRC. ${ }^{34}$ Interestingly, miR-21 has been shown to downregulate $\mathrm{Pdcd} 4$, a $64-\mathrm{kDa}$ protein that inhibits tumor progression by interacting with translation initiation factors elF4A and elF4G, ${ }^{21}$ and this has been suggested as a possible mechanism by which miR-21 might promote tumor invasion and metastasis and potentially influence clinical outcome.

MiR-106a and miR-17-5p are both believed to target the multifunctional E2F1 transcription factor and may as such take part in p53-E2F cross talk in regulating cell proliferation and death. ${ }^{43}$ Low expression of miR-106a was in a panel of
110 CRC samples found to correlate with advanced disease stage and OS, and expression levels were inversely correlated with E2F1 expression levels. ${ }^{19}$ The finding would support miR-106a as a tumor suppressor as loss of negative regulation of E2F1 could result in a proliferative tumor response. However, for miR-17-5p, which also varied inversely with E2F1 expression levels, overexpression was associated with advanced disease stage (although not with OS). This would suggest the opposite biological interpretation although the resulting effect on the effector molecule E2F1 would be expected to be the same. To complicate the picture, Schetter and co-workers found that high expression levels of miR-106a was associated with shorter survival in the test cohort, although the correlation was not confirmed in the validation population. ${ }^{17}$

These results illustrate several important points regarding the interpretation of miRNA expression data, particularly when trying to use the data to explain clinical tumor progression. The lack of standardized test methods for miRNA analysis may in part explain the contradictory results of miR-106a being up-regulated relative to normal tissues in one study and down-regulated in another. The ability of miRNAs to variably influence expression levels of multiple target molecules depending on strand complementarity may make outcome analyses complicated, because several pathways with variable downstream responses may be influenced by one, or in E2F1s case, several miRNAs. When correlating these data to complex, multifactor outcomes, such as survival from cancer, it is not surprising that conclusions may differ.

\section{MiRNAs as Predictive Biomarkers for Chemotherapy Response in CRC}

With the implementation of new drugs and the addition of biological agents, chemotherapy is becoming an increasingly important treatment modality in CRC, particularly in metastatic disease, but also in the neoadjuvant and adjuvant settings. These drugs have significant side effects and treatment is costly, rendering the search for predictive biomarkers important with the aim to possibly individualize treatment. miRNAs have been explored for their association with tumor sensitivity and cellular responses, in particular to fluoropyrimidine based chemotherapy which is one of the mainstays in CRC treatment.

Most of the work studying the relevance of miRNAs in predicting chemotherapy effects and tumor cell sensitivity has been performed using preclinical models, in particular CRC cell lines grown in vitro. In a study of two subclones from the much-used human CRC cell lines HT29 and HCT116, the expression of multiple miRNAs was shown to change on exposure to 5 -fluorouracil (5FU) compared with untreated cells (19 miRNAs were upregulated and 3 down-regulated). ${ }^{44}$ While some changes in miRNA expression were consistent with the antitumor effects of the drug, others were not, such as up-regulation of the polycistronic mir-17-92 cluster (which include miR-19a and miR-20) and miR-21, thought to have antiapoptotic and oncogenic effects and in theory to be involved in drug resistance in these clones. 
Several individual miRNAs have been suggested to be of importance for drug sensitivity in CRC. MiR-192 was shown to down-regulate the anticancer target dihydrofolate reductase which participates in a cycle feedback loop together with thymidylate synthase and is involved in DNA and RNA synthesis. ${ }^{45}$ Dihydrofolate reductase is an important target for antifolate-based anticancer chemotherapy, and its down-regulation could influence 5FU efficacy in CRC, as 5FU blocks thymidylate synthase and therefore also growth and proliferation by inhibiting DNA/RNA synthesis. While miR-192 could indirectly sensitize cells for 5FU, elevated levels of miR-196a, which targets the HoxA7, HoxB8, HoxC8, and HoxD8 genes, increased apoptotic cell death in response to oxaliplatin and cis-platin, but not to 5FU, exposure in the CRC cell line SW480. ${ }^{46}$ However, up-regulation of miR-196a also promoted cell migration and invasion in vitro, as well as increased frequency of lung colony formation on tail vein injection in nude mice, rendering the effects ambiguous. As previously mentioned, miR-143 is expressed at low levels in CRC compared with normal tissues. Experimental up-regulation of miR-143 in HCT116 cells resulted in reduced cell viability and increased apoptotic cell death on 5FU exposure, but its implications in the clinical setting has not been examined. ${ }^{47}$ From a recent study of osteosarcoma xenografts, miR-140 was identified as associated with multiple drug resistance, and subsequent experimental up-regulation by transfection of miR-140 in a CRC cell line (HCT116), resulted in p53-dependent cell cycle arrest accompanied by resistance to 5FU and methotrexate. ${ }^{48}$ MiR-140 was highly expressed in stem-like subpopulations of HCT116 which were also shown to be resistant to $5 F U$ treatment, and this phenotype could be partially reverted by transfection of anti-miR-140, leading the authors to suggest that miR-140 might be a candidate target for developing novel therapeutic strategy to overcome drug resistance.

The task of carrying out prospective studies for identification of predictive markers in clinical cancer therapy is challenging, and often retrospective strategies are implemented. In a study of 46 patients with residual or recurrent colon cancer treated with the 5FU analog S-1, RNA was isolated from formalin-fixed paraffin-embedded samples, followed by RT-PCR analysis of miRNA expression levels. MiRNAs let-7g and miR-181b were shown to be overexpressed in tumor samples relative to normal colon tissues, and the expression was inversely correlated with response to S-1 treatment but had no impact on patient survival. ${ }^{18}$ The above-mentioned reports exploring the potential relevance of miRNAs for chemotherapy response represent important first steps toward identifying possible predictive biomarkers, but verification of targets in adequately designed clinical panels is necessary to assess the potential value of suggested candidates.

\section{MiRNAs as Therapeutic Targets in CRC}

MiRNAs are important biological regulators and are therefore potentially interesting therapeutic targets in cancer. By influencing one miRNA, a cascade of pathways could be affected, and herein exist the potential for sequence specific gene regulation but also the challenge of carefully determining the range of possible desired and undesired effects. Although there are at present no clinical reports describing therapy targeting miRNAs, most authors publishing miRNA results seem to have optimistic views on the future utility of miRNAs as therapeutic targets.

By using antagomirs, modified RNA with the ability to inhibit miRNA by stably and rapidly hybridizing to single stranded RNA, it is possible to inhibit sequence-specific miRNA and study their function in vitro and in vivo. The feasibility of in vivo miRNA inhibition was demonstrated in a proof of principle report in 2005 showing that in mice injected with antagomirs against several miRNAs normal tissue expression of the targets was reduced up to 23 days after a single injection. ${ }^{49}$ However, although these results demonstrate the effectiveness of miRNA inhibition in vivo, the obvious challenge of obtaining tumor cell specificity must be solved to allow clinical implementation. In search of a specific, effective, and stable delivery system, one could look toward progress made with closely related silencing systems such as small interfering RNA (siRNA). Advances have been made using siRNA as a delivery system for cancer therapy through local or targeted administration in vivo, ${ }^{50}$ and the similarity between the miRNA and siRNA systems in silencing mRNA makes the findings applicable to both.

There are several promising potential therapeutic miRNA candidates in CRC, many of which have been mentioned in the previous sections, and if the levels of miRNAs could be manipulated in vivo, effects relevant for cancer progression and treatment efficacy could be obtained. For instance, if levels of let-7g and miR-181b could be lowered, improved response to S-1 treatment might be achieved, while augmenting miR-143 levels could inhibit tumor proliferation. However, it would be important to ascertain comprehensively the biological implications of such manipulations, as well as the downstream effects induced by miRNAs over time. Thus, using miRNA in treatment is an intriguing idea, but effective delivery systems must be available, and for each potential target, the challenge of foreseeing down-stream regulatory effects of manipulating levels of a single miRNA will require extensive research.

\section{Conclusions}

Since their discovery, the field of miRNA research has grown tremendously, and we presently know that these molecules are important regulators of gene expression and may influence cancer development and progression as oncogenes or tumor suppressors depending on effects brought about by targeted mRNAs. The relatively low number of miRNA, the possibility of using standardized, rapid, and relatively inexpensive detection methods suitable for high-throughput analysis, together with their unique chemical stability make miRNAs promising candidates for ex vivo detection as biomarkers of cancer. A number of miRNAs are dysregulated in CRC and have been linked to biological processes relevant for tumor 
growth and progression and for chemotherapy response, as discussed in this review. However, with respect to identifying clinically useful biomarkers we are currently only scratching the surface; a significant amount of research is still required to determine whether any of the mentioned candidates will fulfill their promise.

In this regard, one important task is the clinical validation of already suggested miRNA biomarkers in independent clinical panels, an undertaking that feasible, and most likely broadly ongoing in research groups with access to patient samples. As the number of identified human miRNAs steadily increases, novel candidates will be added to screening tools, and particular attention should be focused toward applying these tools in adequately designed clinical panels. However, the most daunting challenge will be to identify miRNA targets and understand the potentially complex downstream cellular signaling. Although such knowledge is not absolutely necessary for early detection incomplete characterization would hamper the use of biomarkers for prognostic and predictive purposes or as therapeutic targets. Generating a more complete picture of miRNA expression and clinical relevance in CRC and gaining knowledge of targets and cellular effects is a major task, but acknowledging the potential utility of mRNA as biomarkers it is likely to be worth the effort.

\section{References}

1. Lee RC, Feinbaum RL, Ambros V: The C. elegans heterochronic gene lin-4 encodes small RNAs with antisense complementarity to lin-14. Cell 1993, 75:843-854

2. Griffiths-Jones S, Grocock RJ, van Dongen S, Bateman A, Enright AJ: miRBase: microRNA sequences, targets and gene nomenclature. Nucleic Acids Res 2006, 34:D140-D144

3. Lu J, Getz G, Miska EA, Alvarez-Saavedra E, Lamb J, Peck D, Sweet-Cordero A, Ebert BL, Mak RH, Ferrando AA, Downing JR, Jacks T, Horvitz HR, Golub TR: MicroRNA expression profiles classify human cancers. Nature 2005, 435:834-838

4. Esquela-Kerscher A, Slack FJ: Oncomirs - microRNAs with a role in cancer. Nat Rev Cancer 2006, 6:259-269

5. Bartel DP: MicroRNAs: genomics, biogenesis, mechanism, and function. Cell 2004, 116:281-297

6. He L, Hannon GJ: MicroRNAs: small RNAs with a big role in gene regulation. Nat Rev Genet 2004, 5:522-531

7. Vasudevan S, Tong $Y$, Steitz JA: Switching from repression to activation: microRNAs can up-regulate translation. Science 2007, 318:1931-1934

8. Mitchell PS, Parkin RK, Kroh EM, Fritz BR, Wyman SK, PogosovaAgadjanyan EL, Peterson A, Noteboom J, O'Briant KC, Allen A, Lin DW, Urban N, Drescher CW, Knudsen BS, Stirewalt DL, Gentleman R, Vessella RL, Nelson PS, Martin DB, Tewari M: Circulating microRNAs as stable blood-based markers for cancer detection. Proc Natl Acad Sci USA 2008, 105:10513-10518

9. Lewis BP, Burge CB, Bartel DP: Conserved seed pairing, often flanked by adenosines, indicates that thousands of human genes are microRNA targets. Cell 2005, 120:15-20

10. Huang Q, Gumireddy K, Schrier M, le Sage C, Nagel R, Nair S, Egan DA, Li A, Huang G, Klein-Szanto AJ, Gimotty PA, Katsaros D, Coukos G, Zhang L, Pure E, Agami R: The microRNAs miR-373 and miR-520c promote tumour invasion and metastasis. Nat Cell Biol 2008, 10: 202-210

11. Lee DY, Deng Z, Wang CH, Yang BB: MicroRNA-378 promotes cell survival, tumor growth, and angiogenesis by targeting SuFu and Fus-1 expression. Proc Natl Acad Sci USA 2007, 104:20350-20355

12. Ma L, Teruya-Feldstein J, Weinberg RA: Tumour invasion and metas- tasis initiated by microRNA-10b in breast cancer. Nature 2007, 449:682-688

13. Yu SL, Chen HY, Chang GC, Chen CY, Chen HW, Singh S, Cheng CL, Yu CJ, Lee YC, Chen HS, Su TJ, Chiang CC, Li HN, Hong QS, Su HY, Chen CC, Chen WJ, Liu CC, Chan WK, Chen WJ, Li KC, Chen JJ, Yang PC: MicroRNA signature predicts survival and relapse in lung cancer. Cancer Cell 2008, 13:48-57

14. Calin GA, Dumitru CD, Shimizu M, Bichi R, Zupo S, Noch E, Aldler H, Rattan S, Keating M, Rai K, Rassenti L, Kipps T, Negrini M, Bullrich F, Croce CM: Frequent deletions and down-regulation of micro-RNA genes miR15 and miR16 at 13q14 in chronic lymphocytic leukemia. Proc Natl Acad Sci USA 2002, 99:15524-15529

15. Fujita Y, Kojima K, Hamada N, Ohhashi R, Akao Y, Nozawa Y, Deguchi $\mathrm{T}$, Ito $\mathrm{M}$ : Effects of miR-34a on cell growth and chemoresistance in prostate cancer PC3 cells. Biochem Biophys Res Commun 2008, 377:114-119

16. Tazawa H, Tsuchiya N, Izumiya M, Nakagama H: Tumor-suppressive miR-34a induces senescence-like growth arrest through modulation of the E2F pathway in human colon cancer cells. Proc Natl Acad Sci USA 2007, 104:15472-15477

17. Schetter AJ, Leung SY, Sohn JJ, Zanetti KA, Bowman ED, Yanaihara N, Yuen ST, Chan TL, Kwong DL, Au GK, Liu CG, Calin GA, Croce CM, Harris CC: MicroRNA expression profiles associated with prognosis and therapeutic outcome in colon adenocarcinoma. JAMA 2008, 299:425-436

18. Nakajima G, Hayashi K, Xi Y, Kudo K, Uchida K, Takasaki K, Yamamoto M, Ju J: Non-coding MicroRNAs hsa-let-7g and hsa-miR$181 \mathrm{~b}$ are Associated with Chemoresponse to S-1 in Colon Cancer. Cancer Genomics Proteomics 2006, 3:317-324

19. Diaz R, Silva J, Garcia JM, Lorenzo Y, Garcia V, Pena C, Rodriguez R, Munoz C, Garcia F, Bonilla F, Dominguez G: Deregulated expression of miR-106a predicts survival in human colon cancer patients. Genes Chromosomes Cancer 2008, 47:794-802

20. Huang Z, Huang D, Ni S, Peng Z, Sheng W, Du X: Plasma microRNAs are promising novel biomarkers for early detection of colorectal cancer. Int J Cancer 2010, 127:118-126

21. Asangani IA, Rasheed SA, Nikolova DA, Leupold JH, Colburn NH, Post S, Allgayer $\mathrm{H}$ : MicroRNA-21 (miR-21) post-transcriptionally downregulates tumor suppressor $\mathrm{Pdcd} 4$ and stimulates invasion, intravasation and metastasis in colorectal cancer. Oncogene 2008, 27:2128-2136

22. Slaby O, Svoboda M, Fabian P, Smerdova T, Knoflickova D, Bednarikova M, Nenutil R, Vyzula R: Altered expression of miR-21, miR31 , miR-143 and miR-145 is related to clinicopathologic features of colorectal cancer. Oncology 2007, 72:397-402

23. Wang CJ, Zhou ZG, Wang L, Yang L, Zhou B, Gu J, Chen HY, Sun XF: Clinicopathological significance of microRNA-31, -143 and -145 expression in colorectal cancer. Dis Markers 2009, 26:27-34

24. Bandres E, Cubedo E, Agirre X, Malumbres R, Zarate R, Ramirez N Abajo A, Navarro A, Moreno I, Monzo M, Garcia-Foncillas J: Identification by Real-time PCR of 13 mature microRNAs differentially expressed in colorectal cancer and non-tumoral tissues. Mol Cancer 2006, 5:29

25. Ng EK, Chong WW, Jin H, Lam EK, Shin VY, Yu J, Poon TC, Ng SS Sung JJ: Differential expression of microRNAs in plasma of colorectal cancer patients: A potential marker for colorectal cancer screening. Gut 2009, 58:1375-1381

26. Kumar MS, Lu J, Mercer KL, Golub TR, Jacks T: Impaired microRNA processing enhances cellular transformation and tumorigenesis. Nat Genet 2007, 39:673-677

27. Akao Y, Nakagawa Y, Naoe T: MicroRNA-143 and -145 in colon cancer. DNA Cell Biol 2007, 26:311-320

28. Calin GA, Croce CM: MicroRNA-cancer connection: the beginning of a new tale. Cancer Res 2006, 66:7390-7394

29. Volinia S, Calin GA, Liu CG, Ambs S, Cimmino A, Petrocca F, Visone R, lorio M, Roldo C, Ferracin M, Prueitt RL, Yanaihara N, Lanza G, Scarpa A, Vecchione A, Negrini M, Harris CC, Croce CM: A microRNA expression signature of human solid tumors defines cancer gene targets. Proc Natl Acad Sci USA 2006, 103:2257-2261

30. Michael MZ, SM OC, van Holst Pellekaan NG, Young GP, James RJ: Reduced accumulation of specific microRNAs in colorectal neoplasia. Mol Cancer Res 2003, 1:882-891

31. Akao Y, Nakagawa Y, Naoe T: MicroRNAs 143 and 145 are possible 
common onco-microRNAs in human cancers. Oncol Rep 2006, $16: 845-850$

32. Esau C, Kang X, Peralta E, Hanson E, Marcusson EG, Ravichandran LV, Sun Y, Koo S, Perera RJ, Jain R, Dean NM, Freier SM, Bennett CF, Lollo B, Griffey R: MicroRNA-143 regulates adipocyte differentiation. J Biol Chem 2004, 279:52361-52365

33. Shi B, Sepp-Lorenzino L, Prisco M, Linsley P, deAngelis T, Baserga R: Micro RNA 145 targets the insulin receptor substrate- 1 and inhibits the growth of colon cancer cells. J Biol Chem 2007, 282:32582-32590

34. Guo C, Sah JF, Beard L, Willson JK, Markowitz SD, Guda K: The noncoding RNA, miR-126, suppresses the growth of neoplastic cells by targeting phosphatidylinositol 3-kinase signaling and is frequently lost in colon cancers. Genes Chromosomes Cancer 2008, 47:939-946

35. Calin GA, Sevignani C, Dumitru CD, Hyslop T, Noch E, Yendamuri S, Shimizu M, Rattan S, Bullrich F, Negrini M, Croce CM: Human microRNA genes are frequently located at fragile sites and genomic regions involved in cancers. Proc Natl Acad Sci USA 2004 101:2999-3004

36. Toyota M, Suzuki H, Sasaki $Y$, Maruyama R, Imai K, Shinomura $Y$, Tokino T: Epigenetic silencing of microRNA-34b/c and B-cell translocation gene 4 is associated with $\mathrm{CpG}$ island methylation in colorectal cancer. Cancer Res 2008, 68:4123-4132

37. Lawrie CH, Gal S, Dunlop HM, Pushkaran B, Liggins AP, Pulford K, Banham AH, Pezzella F, Boultwood J, Wainscoat JS, Hatton CS, Harris AL: Detection of elevated levels of tumour-associated microRNAs in serum of patients with diffuse large B-cell lymphoma. Br $J$ Haematol 2008, 141:672-675

38. Chen X, Ba Y, Ma L, Cai X, Yin Y, Wang K, Guo J, Zhang Y, Chen J, Guo X, Li Q, Li X, Wang W, Zhang Y, Wang J, Jiang X, Xiang Y, Xu C, Zheng P, Zhang J, Li R, Zhang H, Shang X, Gong T, Ning G, Wang J, Zen K, Zhang J, Zhang CY: Characterization of microRNAs in serum: a novel class of biomarkers for diagnosis of cancer and other diseases. Cell Res 2008, 18:997-1006

39. Hanke M, Hoefig K, Merz H, Feller AC, Kausch I, Jocham D, Warnecke JM, Sczakiel G: A robust methodology to study urine microRNA as tumor marker: microRNA-126 and microRNA-182 are related to urinary bladder cancer. Urol Oncol, doi: 10.1016/j. urolonc.2009.01.027

40. Valadi H, Ekstrom K, Bossios A, Sjostrand M, Lee JJ, Lotvall JO:
Exosome-mediated transfer of mRNAs and microRNAs is a novel mechanism of genetic exchange between cells. Nat Cell Biol 2007, 9:654-659

41. Hunter MP, Ismail N, Zhang X, Aguda BD, Lee EJ, Yu L, Xiao T, Schafer J, Lee ML, Schmittgen TD, Nana-Sinkam SP, Jarjoura D, Marsh CB: Detection of microRNA expression in human peripheral blood microvesicles. PLoS One 2008, 3:e3694

42. Ahmed FE, Jeffries CD, Vos PW, Flake G, Nuovo GJ, Sinar DR, Nazir W, Marcuard SP: Diagnostic microRNA markers for screening sporadic human colon cancer and active ulcerative colitis in stool and tissue. Cancer Genomics Proteomics 2009, 6:281-295

43. Brosh R, Shalgi R, Liran A, Landan G, Korotayev K, Nguyen GH, Enerly E, Johnsen H, Buganim Y, Solomon H, Goldstein I, Madar S, Goldfinger N, Borresen-Dale AL, Ginsberg D, Harris CC, Pilpel Y, Oren M, Rotter V: p53-Repressed miRNAs are involved with E2F in a feed-forward loop promoting proliferation. Mol Syst Biol 2008, 4:229

44. Rossi L, Bonmassar E, Faraoni I: Modification of miR gene expression pattern in human colon cancer cells following exposure to 5-fluorouracil in vitro. Pharmacol Res 2007, 56:248-253

45. Song B, Wang Y, Kudo K, Gavin EJ, Xi Y, Ju J: miR-192 Regulates dihydrofolate reductase and cellular proliferation through the p53microRNA circuit. Clin Cancer Res 2008, 14:8080-8086

46. Schimanski CC, Frerichs K, Rahman F, Berger M, Lang H, Galle PR, Moehler M, Gockel I: High miR-196a levels promote the oncogenic phenotype of colorectal cancer cells. World J Gastroenterol 2009, 15:2089-2096

47. Borralho PM, Kren BT, Castro RE, Moreira da Silva IB, Steer CJ, Rodrigues CM: MicroRNA-143 reduces viability and increases sensitivity to 5-fluorouracil in HCT116 human colorectal cancer cells. FEBS J 2009, 276:6689-6700

48. Song B, Wang Y, Xi Y, Kudo K, Bruheim S, Botchkina Gl, Gavin E, Wan Y, Formentini A, Kornmann M, Fodstad O, Ju J: Mechanism of chemoresistance mediated by miR-140 in human osteosarcoma and colon cancer cells. Oncogene 2009, 28:4065-4074

49. Krutzfeldt J, Rajewsky N, Braich R, Rajeev KG, Tuschl T, Manoharan $\mathrm{M}$, Stoffel M: Silencing of microRNAs in vivo with 'antagomirs'. Nature 2005, 438:685-689

50. Gondi CS, Rao JS: Concepts in in vivo siRNA delivery for cancer therapy. J Cell Physiol 2009, 220:285-291 